\title{
IDENTIFIKASI PERKEMBANGAN KOMUNIKASI ANAK PERVASIVE DEVELOPMENTAL DISORDER
}

\author{
Muhammad Nurrohman Jauhari \\ Program studi PG-PAUD Fakultas Keguruan Dan Ilmu Pendidikan \\ Universitas PGRI Adi Buana \\ muhammadnurrohmanjauhari@yahoo.co.id
}

\begin{abstract}
Abstrak
Komunikasi merupakan bagian terpenting dalam hidup manusia, tanpa adanya komunikasi, manusia tidak dapat berinteraksi dengan manusia lainnya. Peran dasar komunikasi adalah jembatan untuk membangun interaksi sosial antara individu satu dengan individu lainnya. Untuk itu, komunikasi berfungsi sebagai medium bagi pembentukan dan pengembangan pribadi individu melalui kontak sosial Anak pervasive developmental disorder atau dapat disebut dengan ASD (Autism Spectrum Disorder) merupakan suatu gangguan atau ketidaknormalan pada seseorang yang ditandai dengan tidak berkembangnya kemampuan sosial dan komunikasi yang di iringi dengan perilaku repetitive dan restrictive (gangguan minat). Pervasive developmental disorder mempunyai empat klasifikasi, yaitu Autis Disorder, Asperger syndrome, Rett Syndrome, dan PDDNOS (Pervasive Development Disorder-Not Otherwise Specified). Tujuan dalam penelitian ini adalah untuk mengidentiikasi dan mendeskripsikan tahapan komunikasi anak pervasive developmental disorder.

Penelitian ini menggunakan pendekatan kualitatif, jenis penelitian kualitatif yang digunakan adalah studi kasus. Berdasarkan hasil observasi dan pengamatan menunjukan bahwa anak pervasive developmental disorder mempunyai perkembangan komunikasi yang berbeda-beda. Dari hasil penelitian dapat disimpulkan bahwa bahwa perkembangan komunikasi anak Autis Disorder, Asperger syndrome, Rett Syndrome, dan PDD-NOS (Pervasive Development Disorder-Not Otherwise Specified) mempunyai perbedaan berdasarkan karakteristik anak.
\end{abstract}

Kata kunci : komunikasi, anak pervasive developmental disorder, identifikasi

\section{PENDAHULUAN}

Pada dasarnya komunikasi merupakan bagian terpenting dalam hidup manusia, tanpa adanya komunikasi, manusia tidak dapat berinteraksi dengan manusia lainnya. Peran dasar komunikasi adalah jembatan untuk membangun interaksi sosial antara individu satu dengan individu lainnya. Untuk itu, komunikasi berfungsi sebagai medium bagi pembentukan dan pengembangan pribadi individu melalui kontak sosial. Dalam proses komunikasi antara 
individu terjadi kontak sosial melalui penyampaian pesan, penerimaan pesan dan saling berbagi makna bersama, baik makna verbal maupun nonverbal. Komunikasi verbal merupakan komunikasi yang menggunakan bahasa sebagai unsure utamanya, dimana bahasa merupakan suatu bagian yang sangat esensial dari manusia untuk menyatakan dirinya maupun tentang dunia yang nyata. Bagi manusia, bahasa merupakan faktor utama yang menghasilkan persepsi, pendapat, dan pengetahuan.Komunikasi nonverbal adalah pesan yang berbentuk nonverbal, tanpa kata atau bahasa yang dikenal dengan istilah bahasa diam (silent language), fungsinya untuk melengkapi, bahkan menggantikan keberadaan komunikasi verbal, baik itu melalui ekspresi wajah, gerakan tangan dan sebagainya.

Anak pervasive developmental disorder atau dapat disebut dengan ASD (Autism Spectrum Disorder) merupakan suatu gangguan atau ketidaknormalan pada seseorang yang ditandai dengan tidak berkembangnya kemampuan sosial dan komunikasi yang di iringi dengan perilaku repetitive dan restrictive (gangguan minat). Pervasive developmental disorder mempunyai empat klasifikasi, yaitu Autis Disorder,
Asperger syndrome, Rett Syndrome, dan PDD-NOS (Pervasive Development Disorder-Not Otherwise Specified). Dimana empat klasifikasi tersebut merupakan bagian dalam payung gangguan pervasive developmental disorder (DSM V : 2013). Gangguan komunikasi yang dialami anak akan mempengaruhi pertumbuhan, perkembangan dan kemampuan anak, meskipun tidak seluruh aspek pertumbuhan, perkembangan dan kemampuan seseorang ditentukan oleh kemampuan perilaku komunikasinya. Untuk mengetahui perkembangan komunikasi Anak pervasive developmental disorder perlu dilakukan kegiatan mengenal atau menandai sesuatu, yang dimaknai sebagai proses penjaringan atau proses menemukan kasus yaitu menemukan anak yang mempunyai kelainan/masalah atau yang disebut dengan identifikasi

Identifikasi dapat dilakukan oleh orang-orang yang dekat (sering berhubungan/bergaul) dengan anak, seperti orang tuanya, pengasuhnya, gurunya, dan pihak-pihak lain. Identifikasi dilakukan untuk menentukan mengetahui perkembangan komunikasi pada anak Autis Disorder, Asperger syndrome, Rett Syndrome, dan PDD-NOS 
(Pervasive Development Disorder-Not

Otherwise Specified). Tujuan

dilakukannya penelitian ini untuk

memberikan pengetahuan tentang

komunikasi anak pervasive

developmental disorder. karena ke empat gangguan tersebut mempunyai

karakteristik yang berbeda-beda dalam komunikasi.

\section{METODE}

Penelitian ini menggunakan pendekatan kualitatif yang bermaksud untuk memahami fenomena tentang apa yang dialami oleh subjek penelitian, secara holistik, dan dengan cara deskripsi dalam bentuk kata-kata dan bahasa, pada suatu konteks khusus yang alamiah dan dengan memanfaatkan berbagai metode alamiah

Jenis penelitian kualitatif yang digunakan adalah studi kasus. Yang bertujuan mendalami suatu kasus tertentu secara lebih mendalam dengan melibatkan pengumpulan beraneka informasi. Subjek penelitian adalah anak Autis Disorder, anak Asperger syndrome, anak Rett Syndrome, dan anak PDD-NOS (Pervasive Development Disorder-Not Otherwise) antara umur 3-8 tahun. Teknik pengumpulan data dengan cara observasi, wawancara, dokumentasi

\section{HASIL}

1. Anak autis disorder

Berdasarkan hasil obervasi dan pengamatan perkembangan komunikasi anak autis di lembaga esya terapi dapat dideskripsikan sebagai berikut :

Untuk bahasa verbal anak autis mengalami keterlambatan dalam perkembangan bahasa antara lain : pada saat guru menjelaskan anak sering berkata tanpa arti dan menirukan perkataan orang lain secara spontan, paa saat berkomunikasi kepada temannya bahasanya tidak dapat dimengerti oleh lawan bicara, pada saat istirahat anak autis senang meniru atau membeo (echolalia), Bila senang meniru dapat hafal katakata atau nyanyian tersebut tanpa mengerti artinya, Sering berbicara pada diri-sendiri, Sukar mengatur volume dan intonasi suaranya, Kesulitan mengungkapkan perasaan/ emosi melalui suara. Bahasa non verbal : peneliti menemukan perilaku komunikasi nonverbal selama penelitrian, seperti ekpresi bibir datar dengan mata tertutup sedikit menunjukkan rasa ketakutannya ketika terapisnya berbicara dengan suara lantang dan tegas. Selain itu, ekpresi penolakan 
dengan menjauhkan musik tersebut menggunakan tangannya dengan ekspresi wajah bibir datar dengan mengeluarkan suara meringis, menunjukkan tidak sukaannya ketika terapisnya memperdengarkan musik di telinganya. Lebih lanjut, ekspresi bibir melengkung ke bawah dengan mata yang sedikit tertutup menandakan dia senang pada saat dia menyukai musiknya serta ketika dia melihat orang baru. Gerakan mulut yang timbul, hanya menguap mengartikan dia sedang mengantuk dan lelah, terkadang juga dia mengeluarkan suara yang tidak jelas, seperti ingin berbicara. Kontak mata pada anak yang satu ini sangat kurang, perhatiannya sama sekali tidak ada, matanya menerawang, kosong, sesekali melihat bendabenda yang ada di ruangan tersebut dengan mata yang sayu. Gerakan tubuh yang diperlihatkan seperti menggeleng-gelengkan kepala, mengetuk meja ketika dia merasa tidak nyaman dengan kondisinya untuk belajar. Memukul kepalanya beberapa kali untuk mendapatkan rasa nyamannya

Kesimpulan dari deskripsi diatas adalah eterlambatan serta penyimpangan dalam berbicara

menyebabkan anak sukar berkomunikaasi serta tidak mampu memahami percakapan orang lain. anak autis tidak mampu menggunakan isyarat gerak saat berkomunikasi dengan orang lain, sehingga penggunaan bahasa isyarat tidak dapat dilakukan. Suara yang keluar biasanya bernada tinggi dan terdengar aneh, berkecenderungan meniru, terkesaan menghafal katakata tetapi sesungguhnya mereka tidak mampu berkomunikasi. Walaupun pengucapan kata cukup baik, namun banyak mempunyai hambatan saat mengungkapkan perasaan melalui bahasa lisan.

2. anak Asperger syndrome

Berdasarkan hasil obervasi dan pengamatan perkembangan komunikasi anak autis di lembaga esya terapi dapat dideskripsikan sebagai berikut :

berdasarkan observasi anak Asperger syndrome peneliti menemukan perilaku komunikasi verbal dan nonverbal selama proses terapi berlangsung, seperti ekpresi beragam, misalnya ketika dia merasa takut, menangis, mengamuk, marah dan bingung. Ekspresi takut, dia tunjukkan dengan bibir datar, mata sedikit 
tertutup, alis dan kening yang mengkerut. Dia merasa ketakutan ketika terapis yang mengajarnya mengeluarkan suara yang tegas dan lantang. Ekspresi wajah dengan mulut yang sedikit terbuka serta mengeluarkan suara yang pelan, seperti meringis menunjukkan dia sedang menangis. Dia menangis ketika dia lapar dan bekal makanannya tidak ada di dalam tasnya. Dia juga akan mengamuk ketika diacuhkan oleh terapisnya dan marah sembari memukul pintu kelas ketika dia ingin pulang lebih awal tetapi tidak mendapat izin dari terapisnya. terapis akan menjadi sasarannya ketika di dalam kondisinya seperti itu, jilbab akan ditarik, dia pun tidak segan untuk mencakar terapisnya. Pola tidur yang terbalik, membuat ngantuk dan membuat dia kurang konsentrasi sehingga berakibat pada emosi yang tinggi, Emosi yang meladak-ledak membuatnya jarang mengikuti proses belajar, hanya ketika moodnya baik maka proses belajar dapat dilaluinya dengan baik pula tetapi ketika moodnya kurang baik, dia tidak akan mengikuti perintah gurunya untuk belajar. Dia akan berlarian keluar kelas. Selain itu, ekspresi dengan bibir datar, alis dan kening yang mengkerut serta mata mengarah pada peneliti, menunjukkan kebingunan atas keberadaan peneliti, tapi sesekali juga senyuman terlihat pada wajahnya ketika melihat peneliti ada di kelasnya. Meskipun anak mengalami hiperaktif, tetapi untuk masalah kontak mata, dia bisa seikit kontak mata, perhatiannya akan perintah cukup baik. Kontak matanya dapat peneliti lihat ketika dia menyenangi pelajaran yang diberikan, misalnya, memasang puzzle. Selain itu, gerakan tubuh yang diperlihatkannya juga masih kurang, tetapi dia mengerti perintah, jika terapisnya memerintahkannya untuk menulis maka dia akan menulis, diperintahkan untuk duduk, maka dia akan duduk. Dia juga mencoba berinteraksi dengan orang yang baru dia lihat dengan cara memegang tangannya. Komunikasi nonverbal yang lain terlihat ketika dia memberikan tasnya kepada gurunya untuk diambilkan botol air minumnya, serta ketika dia ingin pulang, dia akan memasukkan bukunya ke dalam tas, kemudian memakai tasnya 
Kesimpulan dari deskripsi diatas adalah anak Asperger's syndrome sering dijuluki autis non verbal (bahasa ekspresif kurang, dan bahasa reseptif bagus). Anak Asperger syndrome sedikit melakukan kontak mata saat berbicara dengan seseorang karena mempunyai rmasalah menggunakan ekspresi dan gerak tubuh serta kesulitan memahami bahasa tubuh. Anak Asperger syndrome tidak memiliki kesulitan dalam perkembangan bahasa/linguistik, tetapi cenderung memiliki kesulitan untuk memahami bentuk-bentuk komunikasi non-verbal serta katakata yang memiliki banyak arti seperti itu, dan mereka hanya memahami apa arti kata tersebut, seperti yang ia pahami

3. PDD-NOS

(Pervasive

Development Disorder-Not

Otherwise)

Berdasarkan hasil obervasi dan pengamatan perkembangan komunikasi anak autis di SLB AlAzhar dapat dideskripsikan sebagai berikut :

Berdasarkan pengamatan peneliti menemukan beragam perilaku komunikasi nonverbal dan verbal selama proses belajar berlangsung, seperti bibir datar, mata sedikit tertutup serta kening dan alis mengkerut menunjukkan perasaan takutnya ketika gurunya mengeluarkan suara yang lantang dan tegas. Ekspresi dengan bibir datar, matanya mengarah kepada orang yang baru dia lihat, sorotan mata penasaran menunjukkan kebingungannya ketika bertemu dengan orang baru, seperti peneliti. Ekspresi dengan bibir melengkung ke bawah dan mata sedikit tertutup. Gerakan mulut yang timbul antara lain menguap, ketika meraung-raung dan membeo. Menguap terjadi ketika dia merasa capek dan mengantuk, meraung-raung terjadi ketika dia merasa kurang nyaman. Kontak mata yang terlihat pada anak ini lumayan bagus. Kontak mata terjadi ketika gurunya mengeluarkan suara yang besar dan memerintahkan untuk duduk ketika dia mengamuk,. Pada saat itu, sorot matanya menggambarkan bahwa dia berada dalam tekanan dan ketakutan. Perilaku seperti ini diperlihatkan ketika dia ingin pulang tetapi waktu belajar belum selesai. Kontak mata juga terlihat ketika gurunya menjelaskan matanya menerawang, melihat benda-benda yang ada di 
depannya, hal ini dapat diartikan bahwa dia sedang bosan akan akivitas yang selama proses belajar berlangsung. Anak juga sudah mulai dapat megajak bermain teman, dan menyapa teman pada waktu istirahat, ketika ditanya guru anak bisa menjawab dengan satu sampai dua kata, dia memiliki motorik yang baik, dia mampu mengikuti contoh yang diberikan oleh gurunya, dia juga mampu merapikan peralatan tulisnya, memakai kaos kaki sendiri. Tetapi terkadang, dia menarik tangan kita untuk meminta bantuan, entah itu memasangkan tasnya atau membantunya merapikan alat tulis. Perintah gurunya dapat dilakukan dengan baik olehnya, seperti memasang puzzle, memilih warna serta mencocokkan angka.

Kesimpulan dari deskripsi diatas adalah anak PDD-NOS (Pervasive Development Disorder-Not Otherwise) tidak melakukan kontak mata saat berbicara dengan seseorang karena mempunyai rmasalah menggunakan ekspresi dan gerak tubuh serta kesulitan memahami bahasa tubuh. Anak PDD-NOS

(Pervasive

Development Disorder-Not
Otherwise) tidak memiliki kesulitan dalam perkembangan bahasa karena bahasa ekspresifnya bagus

4. Rett syndrome

Berdasarkan hasil obervasi dan pengamatan perkembangan komunikasi anak autis di lembaga esya terapi dapat dideskripsikan sebagai berikut :

Anak dengan gangguan rett syndrome tidak memiliki kontak mata paa saat diajak berkomunikasi oleh terapisnya, dia hanya melakukan gerakan berulang-ulang, anak sering menangis dan mengamuk tanpa sebab. Pada saat terapi bina diri anak tidak mengikutinya dengan benar karena anak tidak paham mengikuti perintah, terapis hanya bisa membantu untuk melakukan kegiatan terapi. anak sering terlihat Mencederai diri-sendiri dan memperlihatkan rasa cemas yang berlebihan, pada saat penelitian anak mengalami kejang-kajang dan harus diberikan perawatan. Setelah diberikan perawatan anak diajak untuk bermain ayunan, anak sering menutup diri dan menjauhi keramaian.

PEMBAHASAN 
1. Anak autis disorder

Perkembangan komunikasi Anak autis disorder
a) Tidak menoleh jika dipanggil, seperti tidak mendengar
b) Jika diajak bicara tidak ada kontak mata
c) Jika diberikan mainan, sarna sekali tidak merespon
d) Sama sekali tidak berminat untuk bermain dengan teman sebaya
e) Tidak bisa mengekspresikan perasaan gembira, sedih, marah terhadap perintah
d) Sudah mulai meniru kata-kata yang diucapkan orang lan
e) Mulai dapat memperhatikan objek yang ditunjukan
f) Mulai dapat mengekspresikan perasaan, senang dan sedih
g) Mulai dapat menunjukan ekspresi marah
h) Ada minat untuk berinteraksi dengan orang lain
i) Ada kontak mata ketika diajak bicara
f) Terikat pada objek tertentu atau kegiatan tertentu

g) Sama sekali belum bisa Bicara
h) Sangat sering melakukan stimulasi diri
i) Tidak bisa menahan/menunda keinginan sesaat

j) Seolah-olah tidak rnelihat dan tidak mendengar apa yan terjadi

2. Anak Asperger syndrome

Perkembangan komunikasi anak Asperger syndrome
a) Jika menginginkan sesuatu menarik tangan orang lain untuk mengambilnya
b) Jika dipanggil namanya dapat menoleh Sudah ada inisiatif

untuk berinteraksi dengan orang lain

c) Sudah mulai ada pengertian

3. Anak PDD-NOS (Pervasive Development Disorder-Not Otherwise)

Perkembangan komunikasi anak PDD-NOS

(Pervasive

Development Disorder-Not Otherwise)

a) Mulai dapat mengungkapkan keinginan secara verbal

b) Mulai dapat menyatakan penolakan secara verbal

c) Menunjukan minat untuk bermain dengan teman sebaya

d) Sudah dapat mengikuti perintah

e) Tindakan yang dilakukan

f) Sudah memiliki kecakapan bicara timbal balik sudah bertujuan 
g) Ada inisiatif untuk mengawali interaksi dan komunikasi

h) Sudah bisa menjawab pertanyaan pendek

4. Anak Rett syndrome

Perkembangan komunikasi Anak Rett syndrome
a) Tidak menoleh jika dipanggil, seperti tidak mendengar
b) Jika diajak bicara tidak ada kontak mata
c) Jika diberikan mainan, sarna sekali tidak merespon
d) Sama sekali tidak berminat untuk bermain dengan teman sebaya
e) Tidak bisa mengekspresikan perasaan gembira, sedih, marah
f) Sama sekali belum bisa Bicara

\section{SIMPULAN DAN SARAN}

Kesimpulan : Perkembangan komunikasi anak Autis Disorder, Asperger syndrome, Rett Syndrome, dan PDDNOS (Pervasive Development Disorder-Not Otherwise Specified) mempunyai perbedaan berdasarkan karakteristik anak.

Saran : Perlu adanya program pembelajaran individual untuk dapat membantu anak pervasive developmental disorder dalam mengembangkan komunikasi sejak dini agar kemampuan
CVBNMBBVkomunikasi dapat berkembang dengan baik.. Orang tua, guru, terapis harus memahami perkembangan anak sejak dini supaya anak mendapatkan terapi atau penanganan dalam mengembangkan kemampuan komu-nikasi anak

\section{DAFTAR RUJUKAN}

Arikunto, Suharsimi. 2006. Prosedur Penelitian. Jakarta: Rineka Cipta.

Arlington, V.A. 2013. Diagnostik and Stastitical Manual of Mental Disorder, Fifth Edition (DSM 5). Washington.

American Psychiatric Assosiation.

Emzir. (2011). Metodologi Penelitian Kualitatif Analisis Data. Jakarta: PT RajaGrafindo Persada.

Ginanjar, Adriana.S. 2008. Panduan Praktis Mendidik Anak Autis Menjadi Orang Tua Istimewa, Jakarta: Dian Rakyat.

Hermanto. 2010. Kemampuan Guru Dalam Melakukan Identifikasi Anak Berkebutuhan Khusus Di Sekolah Dasar Penyelenggara Pendidikan Inklusi. Universitas Negeri Yogyakarta

Kauffman, Walter. 2013. Symphosium: The New Diagnostig Criteria for Autism Spectrum Disorder. Departement of Neurology Boston Children's Hospital.Harvard Medical School. Harvard. 
Moleong, Lexy J. (2012). Metodologi

Penelitian Kualitatif Edisi

Revisi. Bandung: PT Remaja

Rosdakarya.

Mulyana, Deddy. 2007. Ilmu Komunikasi Suatu Pengantar. Bandung: PT Remaja Rosdakarya.

Nana Syaodih Sukmadinata. (2011). Metode Penelitian Pendidikan. Bandung: PT Remaja Rosdakarya.

Raco, J.R. (2010). Metode Penelitian Kualitatif (Jenis, kharakteristik, dan Keunggulannya). Jakarta: PT. Gramedia Widiasarana Indonesia.

Richard West, \& Turner, Lynn $\mathrm{H}$. 2008. Pengantar Teori Komunikasi: Analisis dan Aplikasi, Edisi 3, Buku 1, terj. Maria Natalia Damayanti Maer. Jakarta: Salemba Humanika.

Robert K. Yin. (2006). Studi Kasus; Desain dan Metode. Jakarta : PT Raja Grafindo Persada.

Sugiyono. 2009. Metode Penelitian Kuantitatif, Kualitatif, dan R\&D. Bandung: Alfabeta.

Sunardi \& Sunaryo. (2007). Intervensi Dini Anak Berkebutuhan Khusus. Jakarta: Departemen Pendidikan Nasional.

Turner, Lynn, 2008, Pengantar Teori Komunikasi: Teori dan Aplikasi, Jakarta: Salemba.Humani 
